\title{
Review
}

\section{The impacts of climate change on marine mammals: early signs of significant problems}

\author{
Mark P. Simmonds and Stephen J. Isaac
}

\begin{abstract}
Climate change is now known to be affecting the oceans. It is widely anticipated that impacts on marine mammals will be mediated primarily via changes in prey distribution and abundance and that the more mobile (or otherwise adaptable) species may be able to respond to this to some extent. However, the extent of this adaptability is largely unknown. Meanwhile, within the last few years direct observations have been made of several marine mammal populations that illustrate reactions to climate change. These observations indicate that certain species and populations may be especially vulnerable, including those with a limited habitat range, such as the vaquita Phocoena sinus, or those for which sea ice provides an important part of their habitat, such as narwhals Monodon monoceros, bowhead Balaena mysticetus and beluga Delphinapterus leucas whales and polar bears Ursus maritimus. Similarly, there are concerns about those species that migrate to
\end{abstract}

feeding grounds in polar regions because of rapidly changing conditions there, and this includes many baleen whale populations. This review highlights the need to take projected impacts into account in future conservation and management plans, including species assessments. How this should be done in an adequately precautionary manner offers a significant challenge to those involved in such processes, although it is possible to identify at this time at least some species and populations that may be regarded as especially vulnerable. Marine ecosystems modellers and marine mammal experts will need to work together to make such assessments and conservation plans as robust as possible.

Keywords Climate change, conservation management, dolphins, marine mammals, polar bears, porpoises, seals, whales.

\section{Introduction}

The expert reviews provided by the Intergovernmental Panel on Climate Change (IPCC) make it clear that climate change will induce temperature changes and associated adjustments in ocean circulation, ice coverage and sea level (McCarthy et al., 2001). Changes in the frequency of extreme events are also predicted and these changes, in turn, will affect marine ecosystem structure and functioning, with feedback to global biogeochemical cycles and the climate system. The IPCC has also shown that there has been a general warming of a large part of the world's oceans in the last 50 years, although there are regional variations, and an associated rise in sea

Mark P. Simmonds (Corresponding author) The Whale and Dolphin Conservation Society, Brookfield House, 38 St Paul St, Chippenham, Wiltshire SN16 1LJ, UK. E-mail mark.simmonds@wdcs.org

Stephen J. Isaac Enfusion Ltd, Treenwood House, Rowden Lane, Bradford on Avon, BA15 2AU, UK.

Received 13 February 2006. Revision requested 1 August 2006 Accepted 5 October 2006. levels, and that marine mammals and seabirds are sensitive indicators of changes in ocean environments.

Here we review the evidence linking changes in populations of marine mammals to changes in global climate, including the known impacts resulting from major natural circulation fluctuations such as the El Niño/Southern Ocean Oscillation. However, trying to predict the precise consequences of climate change for most wildlife is difficult and this is especially true for highly mobile marine mammals. Their marine habitats mean that most species are inherently difficult (and expensive) to study, and long-term data sets defining range and habitat are typically rare. The links between global climate change and predator responses are only now being explored (Forcada et al., 2005) and patterns and trends in species diversity in the open oceans remain enigmatic (Worms et al., 2005). The effects of climate change on higher trophic levels can be particularly difficult to investigate because they involve relationships that may be non-trivial, nonlinear and affected by time lags (Lusseau et al., 2004; Leaper et al., 2006). The constraints of existing climate models 
severely limit the ability to predict the responses of particular species (IWC, 1996) although predictive power is expected to improve.

Sea surface temperature is a good predictor for marine mammal distributions (Robinson et al., 2005; Kaschner et al., 2006). Some species are found exclusively in warm tropical waters, some in the temperate zone and others only at the poles. Whilst a few species may move between different temperature zones during regular migrations, they may be adapted to particular temperature regimes at particular stages of their life cycles. For example, young marine mammals may require relatively warmer waters (Simmonds, 2004). Marine mammals typically exploit patchy prey species that they require in dense concentrations and hence their distribution tends to reflect those oceanic features, both static (such as depth and slope) and more mobile (such as fronts and upwellings), where productivity is high.

A list of all of the species of marine mammals mentioned in this review, with their category on the IUCN Red List, is provided in Table 1. Many of the species are already threatened to varying extents, and this is without the factoring of climate change impacts into the assessments. The status of most marine mammals was last reviewed in 1996. A new assessment is now due for many of these species and faces the challenge of how to factor in increased, but unclear, vulnerabilities resulting from climate change.

\section{Predictions}

Eleven years ago MacGarvin \& Simmonds (1996) considered the likely impacts of climate change on cetaceans and commented that 'amongst the many environmental threats faced by cetacean populations the most speculative, and yet perhaps potentially the most important, concern the implications for them of changes in atmosphere and climate'. They suggested that cetaceans would be affected by changes in their prey both in terms of productivity and shifts in distribution of prey species, and that negative effects at the base of marine food webs could be created by changes in water temperature, turbulence and surface salinity. They highlighted five other related issues: (1) The rate of climate change is outside the evolutionary experience of existing cetacean species. (2) Many whale

Table 1 The species of marine mammal mentioned in this review, with their Red List category (IUCN, 2006). All species were last assessed in 1996 except for the polar bear, which was assessed in 2006.

\begin{tabular}{|c|c|c|}
\hline Species & Common English name & Red List category* \\
\hline \multicolumn{3}{|l|}{ Cetaceans } \\
\hline Balaena mysticetus & Bowhead whale & $\mathrm{LR} / \mathrm{cd}$ \\
\hline Balaenoptera acutorostrata & Common minke whale & $\mathrm{LR} / \mathrm{nt}$ \\
\hline Balaenoptera physalus & Fin whale & EN \\
\hline Delphinapterus leucas & Beluga whale & VU \\
\hline Delphinus delphis & Common dolphin & $\mathrm{LR} / \mathrm{lc}$ \\
\hline Eschrichtius robustus & Grey whale & $\mathrm{LR} / \mathrm{cd}$ \\
\hline Eubalaena glacialis & North Atlantic right whale & EN \\
\hline Eubalaena australis & Southern right whale & $\mathrm{LR} / \mathrm{cd}$ \\
\hline Globicephala macrorhynchus & Short-finned pilot whale & $\mathrm{LR} / \mathrm{cd}$ \\
\hline Grampus griseus & Risso's dolphin & DD \\
\hline Lagenorhynchus albirostris & White-beaked dolphin & $\mathrm{LR} / \mathrm{lc}$ \\
\hline Megaptera novaeangliae & Humpback whale & VU \\
\hline Monodon monoceros & Narwhal & $\mathrm{DD}$ \\
\hline Orcinus orca & Orca/killer whale & $\mathrm{LR} / \mathrm{cd}$ \\
\hline Phocoena phocoena & Harbour porpoise & VU \\
\hline Phocoena sinus & Vaquita & $\mathrm{CR}$ \\
\hline Physeter macrocephalus & Sperm whale/cachalot & VU \\
\hline Stenella coeruleoalba & Striped dolphin & $\mathrm{LR} / \mathrm{cd}$ \\
\hline Tursiops truncatus & Common bottlenose dolphin & DD \\
\hline \multicolumn{3}{|l|}{ Pinnipeds } \\
\hline Arctocephalus galapagoensis & Galapagos fur seal & VU \\
\hline Arctocephalus gazella & Antarctic fur seals & $\mathrm{LR} / \mathrm{lc}$ \\
\hline Odobenus rosmarus & Walrus & $\mathrm{LR} / \mathrm{lc}$ \\
\hline Pagophilus groenlandicus & Harp seal & $\mathrm{LR} / \mathrm{lc}$ \\
\hline \multicolumn{3}{|l|}{ Carnivores } \\
\hline Ursus maritimus & Polar bear & VU \\
\hline
\end{tabular}

${ }^{*} \mathrm{CR}$, Critically Endangered; EN, Endangered; VU, Vulnerable; DD, Data Deficient; LR, Lower Risk (lc, least concern; nt, near threatened; cd, conservation dependent). LR/lc means that the species has been evaluated and is not on the Red List. All categorizations are based on v. 2.3 of the IUCN Red List (IUCN, 1994) except that of the polar bear, which is based on v. 3.1 (IUCN, 2001). 
species have complicated life cycles and appear to be dependent on finding certain resources in certain places at certain times (for example, water of a certain temperature range or copious prey; examples include whale species that make long annual migrations between feeding and breeding grounds). (3) Movement of water bodies and changes in temperature could affect the ability of whales to navigate across the oceans. (4) Many whale populations are already at extremely low levels. (5) Species and populations are concurrently being negatively affected by other factors. In addition, MacGarvin \& Simmonds (1996) speculated that coastal habitats, such as estuaries, bays and lagoons, may be lost to rising sea levels, which may also exacerbate pollution by inundating coastal landfill sites or agricultural land.

The International Whaling Commission (IWC) held a workshop on climate change in 1995. It reported problems in making predictions but, in addition, stated that 'concerns about the ability of at least some cetacean populations to adapt to future conditions are justified' (IWC, 1996). Burns (2002) emphasized the importance of environmental changes in Antarctica, where $90 \%$ of the world's great whales feed, noting the importance of the relationship between krill Euphausia spp. and the extent of sea ice (Brierly et al., 2002). Sea ice edge may shelter krill from predators and sea ice algae are a critical food resource for krill. Where the sea ice recedes, salps (tunicates of the species Salpa thompsoni) tend to dominate and may outcompete the krill. The salps are more tolerant of warmer and lower nutrient water than krill and there is evidence that their range is expanding, with profound implications for the Southern Ocean food web, including penguins, albatrosses, seals and whales, all of which have wide foraging ranges but are susceptible to krill shortages (Atkinson et al., 2004). Whilst there is an important distinction between land-based predators that rely on localized krill at critical times during the raising of heir young and whales that are potentially more mobile, whales respond to the same climate driven signals as seals and penguins (Leaper et al., 2006).

In the Arctic no one species of plankton dominates, unlike the situation in the Southern Ocean, and a diminution of phytoplankton populations, with knock-on effects throughout the Arctic food chains, is predicted. Several key prey species for cetaceans may be affected but some cetacean species in the region, such as fin whales Balaenoptera physalus and bowhead whales Balaena mysticetus, have demonstrated adaptability in feeding behaviour and may be able to switch to other species (Burns, 2002). Areas of open water in the polar ice pack, known as polynyas or leads, are important for some species of marine mammals, for example as feeding, breeding and over-wintering sites, and their extent may be affected by climate change (Burns, 2002).
Simmonds \& Mayer (1997) reported an apparent increase in mass die-offs in marine mammal populations in recent years and Burns (2002) further noted that global warming may foster poisonous algal blooms and contribute to epizootics. Whilst, in many cases, viruses (notably of the highly pathogenic morbillivirus family) have been identified as the proximate cause of several major mortality events, environmental factors may have exacerbated or even predicated these epizootics (Simmonds \& Mayer, 1997). An example is the die-off of striped dolphins Stenella coeruleoalba that spread across the entire Mediterranean in the 1990s and resulted in the loss of thousands of animals. The poor nutritional state of the dolphins resulting from low nutrient input to the eastern Mediterranean, caused originally by abnormally low rainfall, may have been a precipitating factor (Simmonds \& Mayer, 1997).

Würsig et al. (2002) predicted that species dependent on limited patches of particular types of habitat, such as land- or ice-breeding pinnipeds, coastal and freshwater cetaceans, and sirenians, will be particularly vulnerable to climate change. They noted that even the more mobile ice-edge species, such as the bowhead and beluga Delphinapterus leucas, may be affected by changes in the distribution or quantity of prey. The potential for a significant shift in the Gulf Stream in the North Atlantic and the possibility that the North-west passage across North America will become more easily navigable could result in more boat traffic and increase the risks of oil spills, chemical, acoustic and other pollution, and thus degrade what is currently regarded as a relatively pristine area (Würsig et al., 2002).

Würsig et al. (2002) recommended a classification system for climate effects, with primary effects being experienced by the individual, secondary effects referring to those that affect a population or species, and tertiary effects those created as a response to climate change by humans (for example, climate change-driven fisheries failures may cause human fishers to shift their attention to marine mammals). We will not consider tertiary effects further here, but they are likely to be a significant source of further impacts on some marine mammal populations.

\section{Predator-prey relationships}

El Niño events are important as a proxy for climate change (although a change in the incidence of El Niño events could be a feature of climate change itself; Würsig et al., 2002). Recent El Niño events have prompted reproductive failure, especially in the form of high juvenile mortality, in colonies of seabirds and seals (Würsig et al., 2002). For example, in the El Niño year of 1982 all female Galapagos fur seals Arctocephalus 
galapagoensis lost their pups and several distributional shifts occurred simultaneously in other marine species. Near-bottom spawning market squid Loligo opalescens left the southern California area, followed by at least one of their predators, the short-finned pilot whale Globicephala macrorhynchus. Whether this loss of prey and apparently climate-induced shift led to deaths or health impairment is not known. Several years later an influx of Risso's dolphins Grampus griseus into the same region followed and they fed on market squid, which had by then returned. The dolphins may have been taking advantage of the niche left by the pilot whales (Würsig et al., 2002). Furthermore, during the same event, there was an expansion of common bottlenose dolphins Tursiops truncatus from southern to central California and they remained there after the El Niño event ended (Würsig et al., 2002).

Lusseau et al. (2004) discovered a climate-driven signal in the first study to identify a link between climate variation and social behaviour in a marine system. Using two unusually long-term and detailed data sets, they found that the group size of common bottlenose dolphins in the Moray Firth, Scotland, and orcas Orcinus orca in Johnstone Strait, Canada, varied from year to year in relation to large scale ocean climate variation. Local indices of prey abundance varied with climate and the cetaceans tended to live in smaller groups when there were less salmon, which appeared to occur 2 years after a lower phase of the North Atlantic and Pacific Decadal Oscillations (these are regular patterns in sea surface temperatures; the North Pacific one oscillates over periods of 15-25 years and 50-70 years, and the North Atlantic Oscillation has a dominant period of 12 years). This changing of group size is another illustration of the adaptability of large marine predators.

The stranding of hundreds of grey whales Eschrichtius robustus along the east coast of the Americas in 1999 2000 may have been caused by a decline in their prey in the Chirikov Basin of the Bering Sea, which consequently led to starvation (Moore et al., 2003; Gulland et al., 2005). The abundance and biomass of the grey whale's amphipod prey species had been in decline in the northern Bering Sea since the 1980s and the amphipod species composition in this region shifted to favour species that are less lipid-rich and hence less nutritious (Moore et al., 2003). These changes are thought to have been caused by changing oceanographic conditions and warming seas, and apex predators such as grey whales and walruses Odobenus rosmarus that feed directly on benthic bivalves and amphipods were probably significantly affected by these changes to their prey base (Grebmeier \& Dunton, 2000).
In addition to contributing to climate change another by-product of increasing atmospheric $\mathrm{CO}_{2}$ concentrations is the acidification of sea water. Squid, which are key prey species for many deep-diving marine mammal species, may be especially vulnerable to this change because their high energy swimming method and their high metabolism require a good supply of oxygen; increasing $\mathrm{CO}_{2}$ concentration lowers blood $\mathrm{pH}$ and its capacity to carry oxygen (TRS, 2005). Calcifying organisms, including coral and some phytoplankton and zooplankton species, are also likely to be affected adversely by acidification, with potential knock-on effects for marine predators (TRS, 2005).

\section{Distribution shifts}

The importance of temperature in species distribution in the oceans appears to follow a general rule: diversity is positively correlated with thermal fronts and dissolved oxygen, and is a non-linear function of temperature, with an optimum of about $23^{\circ} \mathrm{C}$ (Worms et al., 2005). As it is to be expected that predator demography will be affected by prey, changes in prey distribution or abundance may precede shifts or declines in predator populations. On a large scale it is predicted that colder water species will shift towards the poles and, ultimately, this will probably result in a reduced global range for these species. Perry et al. (2005) examined long-term, climate-related changes in demersal fish in the North Sea. They found that both exploited and nonexploited fish responded markedly to recent increases in sea temperature, with nearly two-thirds of species shifting their mean latitude or depth (or both) over a 25 -year period. There is some evidence that predators are following the same pattern. Data for cetacean strandings and sighting frequency and relative abundance in north-west Scotland suggested a range expansion of common dolphins Delphinus delphis (a warmer water species) and a decrease in range of white-beaked dolphins Lagenorhynchus albirostris, and this may be the first direct evidence that this pole-ward shift is happening in a cetacean species (MacLeod et al., 2005).

A recent large-scale survey of the European Atlantic continental shelf suggests there has also been a redistribution of harbour porpoises Phocoena phocoena in the North Sea over the last 10 years, with a notable increase in densities in the southern region (K. MacLeod, pers. comm.). This is supported by some sighting and strandings data (although strandings are not necessarily good indicators of distribution). Similarly it has been suggested, based on strandings data, that there is a change in sperm whale Physeter macrocephalus distribution in the north-east Atlantic, and this has been related 
to shifts in the North Atlantic Oscillation that could affect squid prey species (Robinson et al., 2005).

Whilst some cetaceans regularly travel long distances, many undertaking remarkably long annual migrations, others are confined to certain sea areas (Simmonds, 2004). One example is the vaquita Phocoena sinus, which has its entire, and increasingly depleted, population located in the northern part of the Gulf of Mexico. Moreover, even amongst those species that are normally regarded as highly migratory there are populations with limited distributions. For example, both the humpback whales Megaptera novaeangliae in the northern Indian Ocean and the fin whales in the Mediterranean appear confined to these sea areas. It can be argued that species such as the vaquita are particularly vulnerable to climate change because they cannot simply move away from adverse changes within their ranges (the vaquita, for example, cannot move north because there is a land barrier) and the same may prove to be true for other marine mammal populations with limited ranges. Conversely, whales that regularly migrate are especially vulnerable because changes can affect them in any part of their migratory ranges (MacGarvin \& Simmonds, 1996). A whale, for example, arriving at its polar feeding ground does so when its energy reserves are depleted by the requirements of breeding and of its migratory journey. It may therefore be essential for its survival to find food within a certain time-frame.

\section{Sea ice changes}

Ice-breeding seals are strongly affected by the extent of available ice. For example, harp seal Pagophilus groenlandicus pup mortality in the Gulf of St Lawrence, Canada, has been estimated as high as $75 \%$ in poor ice years (Hammill \& Stenson, 2003) and ice conditions in this area have also been linked to the North Atlantic Ocilation (Johnston et al., 2005). The polar bear Ursus maritimus lives throughout the ice-covered waters of the Arctic and particularly on near-shore annual ice cover above the continental shelf, where productivity is highest (Derocher et al., 2004). Climate change models predict changes to the sea ice leading to reduced seal prey for polar bears. Initially, polar bears may be favoured by an increase in leads in the ice that make more suitable seal habitat available but, as the ice thins further, they will have to travel more, using energy to keep in contact with favoured habitat (Derocher et al., 2004). Given the rapid pace of ecological change in the Arctic and the long generation time and specialized habits of polar bears it is unlikely they will survive as a species if the ice disappears completely (Derocher et al., 2004). The polar bear has been described as an ideal species through which to monitor human-caused impacts in the arctic ecosystem, including climate change (WWF, 2002). In the Hudson and James Bays, Canada, sea ice is now melting earlier in the spring and forming later in the autumn and, therefore, the time that the bears have on the ice, storing up energy for the summer and autumn when there is little available food, is becoming shorter (WWF, 2002). In Hudson Bay the main cause of death for cubs is either an absence of food or lack of fat on nursing mothers.

Climate change can, and probably already is, causing different effects in different regions. In Baffin Bay and the adjacent Davis Straight (between Canada and Greenland), strong increasing trends in winter sea ice concentrations were reported for 1979-1996 (Laidre \& Heide-Jørgensen, 2005). Baffin Bay also hosts the largest concentrations of wintering narwhals Monodon monocerus, which are entirely dependent on leads and cracks in the ice for breathing. Major mortality events have been recorded when the narwhals have become trapped in the ice and, given their high site fidelity and the decrease in open water areas, these polar specialists seem particularly vulnerable to climate change (Laidre \& Heide-Jørgensen, 2005).

\section{Impact on breeding success}

Pinnipeds are generally easier to monitor than cetaceans and the breeding assemblages of Antarctic fur seals Arctocephalus gazella at South Georgia have been monitored since the summer of 1984/1985. Analysis of these data has indicated that positive sea surface temperature anomalies at South Georgia preceded by, and cross-correlated with, frequent El Niño-La Nina events between 1987 and 1998 explained extreme reductions in Antarctic fur seal pup production over a 20-year study period (Forcada et al., 2005). These anomalies were probably associated with low availability of prey, mainly krill.

A link has been demonstrated between climate change and the reproductive success of the southern right whale Eubalaena australis, which is the more numerous of the two right whale species (Leaper et al., 2006). Comparison of calving rate in Argentina to sea surface temperatures in the south-west Atlantic and the El Niño 4 region (in the western Pacific) showed that there was a strong relationship between calving success and temperature anomalies at South Georgia in the autumn of the previous year and also with mean El Niño 4 temperature anomalies delayed by 6 years.

There are other signals from cetaceans that breeding is, or will be, affected. Sperm whale populations were heavily affected by commercial whaling and recovery of these slow breeding animals is protracted. Climate change may further impair any recovery and the 
reproductive success of this species in waters near the Galápagos Islands has been associated with periods of warm sea surface temperature, usually caused by El Niño events (Whitehead, 1997).

For the North Atlantic right whale Eubalaena glacialis climate change may be the agent that prevents its recovery and pushes it to final extinction. Following the ending of commercial whaling this cetacean was expected to recover slowly. However, population growth slowed in the 1990s, with collisions with shipping and fishing net entanglement identified as the chief threats. The relatively high abundance in the 1980s of the planktonic copepod Calanus finmarchicus (the principle food for right whales) explained the stable calving rate at that time, and the decline of this copepod in the early 1990s was associated with a drop in calving (Greene \& Pershing, 2004). However, in 1996 the North Atlantic Oscillation Index exhibited its largest single annual fall of the 20th century, leading to negative conditions, and this had profound effects on the north Atlantic's physical and biological oceanography. Effects in the Gulf of Maine/Scotian Shelf region were not seen until 1997-1998, including a dramatic decline in the calving rates of the North Atlantic right whale.

It is difficult to predict the impacts of climate change on whales at a regional level (Greene \& Pershing, 2004). The North Atlantic Ocean Index has been mainly positive over the last 25 years; this should provide favourable conditions for right whale feeding and, therefore, breeding. However, one of the IPCC conclusions is that there will be an increase in climate variability, and Greene \& Pershing (2004) questioned whether the situation in 1996 was unusual or a sign of the expected future swings in climate. The worst scenario would be a prolonged period of negative North Atlantic Ocean conditions (characterized by westerly winds being weaker or less persistent, and a colder and drier northern Europe, whereas southern Europe is warmer and wetter than average). If right whale calving rates were depressed for a significant period then time to extinction would become even shorter than the 200 years currently predicted. Climate change and variability clearly need to be taken into account in the management of the recovery of this population (Greene \& Pershing, 2004) and meanwhile the primary threats to the population, ship strikes and entanglement in nets, need to be urgently addressed.

\section{Conclusions}

Climate change is moving towards the top of the political agendas of some countries at least. For example, the recent UK government report on the economic aspects of climate change concluded that 'the scientific evidence is now overwhelming: climate change presents very serious global risks, and it demands an urgent global response' (Stern, 2006). What is less clear is to what extent climate change is being factored into plans for nature conservation, and this is particularly lacking in the context of the marine environment. However, despite the difficulty involved in monitoring mobile marine species, concerns for their conservation are increasingly underpinned by observed changes linked to climate fluctuations. Where sufficiently long time series of data on marine mammal populations exist, and have been analysed, relationships with climate have generally been found, even in the case of depleted populations. The probable negative consequences for species that have habitat and prey needs linked to the extent of sea ice are relatively clear, although impacts are expected to vary regionally.

Whilst there is evidence that the long-lived and slow breeding ice-edge specialists, the bowhead whales, have been able to change their patterns of habitat use several times in the last 11,000 years, the key question is how quickly marine mammal species can adapt. This concern is accentuated by the prediction that climate change may generate short-term extremes or climate instability.

Leadership should also come from those international fora that deal with species conservation, and these bodies will be important for the provision of coordination and direction. The IWC, for example, has at least recognized the need to address environmental change issues, including the possible impacts of climate change. However, despite the establishment of a working group on environmental matters within its Scientific Committee, it has been suggested that its efforts in this regard have been inadequate. Burns (2002) commented that if the Commission failed to develop its environmental work then its 'ultimate legacy may be that it saved whales from extinction by commercial harvesting but failed them in their time of greatest need'. It is also of concern that in 2006 a resolution in favour of the resumption of commercial whaling was passed (albeit by a majority of one) at the annual IWC meeting. Whilst the ongoing moratorium on commercial whaling was not removed (this would require three quarters of those voting to be in favour), the vote signalled a change at the Commission and, a short time later, Iceland awarded itself a commercial quota of fin whales and minke whales Balaenoptera acutorostrata. These moves towards a resumption of commercial whaling are at odds with growing concerns about the impacts of climate change on marine mammals.

Another convention that might be expected to provide leadership is the Convention for Migratory Species. This body held a workshop on climate change and migratory species at its 2005 Conference of Parties, and seems to be 
preparing to meet the challenges presented by climate change to nature conservation (in particular with respect to the species on its Appendices).

Whilst we have little information about the extent of the adaptability to change of any marine mammal species, overall the available evidence suggests that many populations are highly vulnerable to the impacts of climate change. As this information is increasing, so too is knowledge of climate change processes and their likely impacts on marine and terrestrial ecosystems. One important product of this will be the fourth report by the IPCC, due in 2007. It is increasingly clear that future conservation and management regimes for marine mammals need to take climate change into account. Failure to take this precautionary step could mean that predictions of population status or the robustness of a species or population will be in error, leading to actions that fail in due course to achieve their conservation or management aims. These processes and species assessments, such as those used to develop the IUCN Red List, now face the challenge of determining how to allow for climate change threats. We urge, in terms of such threat assessment processes, that particular weighting is given to the vulnerability of all the species and populations living permanently in polar regions, those that need to migrate to these regions to find their primary food resources, and those species with restricted ranges that may not be able to move away from adverse changes. To make the most robust predictions, marine species experts should work closely with those modelling ocean processes.

\section{Acknowledgements}

This paper was developed from a presentation made at the 2004 Conference of Parties of the Convention of Migratory Species and we are grateful to those, in particular Bill Perrin, who subsequently commented on the presentation. We also thank Russell Leaper, an anonymous reviewer and the editor for comments that greatly improved this article.

\section{References}

Atkinson, A., Siegel, V., Pakhomov, E. \& Rothery, P. (2004) Long-term decline in krill stock and increase in salps within the Southern Ocean. Nature, 432, 100-103.

Brierly, A.S., Fernandez, P., Brandon, M., Armstrong, F. \& Millard, N. (2002) Antarctic krill under sea ice: elevated abundance in a narrow band just south of Ice Edge. Science, 295, 1890-1892.

Burns, W.C.G. (2002) Climate change and the International Whaling Commission in the 21st century. In The Future of Cetaceans in a Changing World (eds W.G.C. Burns \& A. Gillespie), pp. 339-379. Transnational Publishers, New York, USA.
Derocher, A.E., Lunn, N.J. \& Stirling, I. (2004) Polar bears in a warming climate. Integrative and Comparative Biology, 44, 163-176.

Forcada, J., Trathan, P.N., Reid, K. \& Murphy, E.J. (2005) The effects of global climate variability in pup production of Antarctic fur seals. Ecology, 86, 2408-2417.

Grebmeier, J.M. \& Dunton, K.H. (2000) Benthic processes in the northern Bering/Chukchi Seas: status and global change. In Impacts of Changes in Sea Ice and Other Environmental Parameters in the Arctic. Report of the Marine Mammal Commission Workshop, 15-17 February 2000 (ed. H.P. Huntington), pp. 61-71. Marine Mammal Commission, Bethesda, USA.

Greene, C.H. \& Pershing, A.J. (2004) Climate and the conservation biology of North Atlantic right whales: the right whale at the wrong time? Frontiers in Ecology and the Environment, 2, 29-34.

Gulland, F.M.D., Pérez-Cortés, M., Urbán, R., Rojas-Bracho, L., Ylitalo, G., Weir, J., Norman, S.A., Muto, M.M., Rugh, D.J., Kreuder, C. \& Rowles, T. (2005) Eastern North Pacific Gray Whale (Eschrichtius robustus) Unusual Mortality Event, 19992000. NOAA Technical Memorandum NMFS-AFSC-150-150. US Department of Commerce, Washington, DC, USA.

Hammill, M.O. \& Stenson, G.B. (2003) Harvest Simulations for 2003-2006 Harp Seal Management Plan. Report for the Canadian Science Advisory Secretariat, Ottawa, Canada [http://www.dfo-mpo.gc.ca/csas/Csas/DocREC/2003/ RES2003_068_E.pdf, accessed 15 November 2006].

IUCN (1994) 1994 Categories and Criteria (version 2.3). IUCN, Gland, Switzerland [http://www.redlist.org/info/ categories_criteria1994.html, accessed 16 November 2006].

IUCN (2001) 2001 Categories and Criteria (version 3.1). IUCN, Gland, Switzerland [http://www.redlist.org/info/ categories_criteria2001.html, accessed 16 November 2006].

IUCN (2006) 2006 IUCN Red List of Threatened Species. IUCN, Gland, Switzerland [http://www.redlist.org, accessed 16 November 2006].

IWC (1996) Report of the International Whaling Commission Workshop on Climate Change and Cetaceans. Report of the International Whaling Commission, 47, 291-320.

Johnston, D.W., Frienlaender, A.S., Torres, L.G. \& Lavigne, D.M. (2005) Variation in sea ice cover on the east coast of Canada from 1969 to 2002: climate variability and implications for harp and hooded seals. Climate Research, 29, 209-222.

Kaschner, K., Watson, R., Trites, A.W. \& Pauly, D. (2006) Mapping world-wide distributions of marine mammal species using a relative environmental suitability (RES) model. Marine Ecology Progress Series, 316, 285-310.

Laidre, K.L. \& Heide-Jørgensen, M.P. (2005) Arctic sea ice trends and narwhal vulnerability. Biological Conservation, 121, 509-517.

Leaper, R., Cooke, J., Trathan, P., Reid, K., Rowntree, V. \& Payne, R. (2006) Global climate drives southern right whale (Eubalaena australis) population dynamics. Biology Letters, 2, 289-292.

Lusseau, D., Williams, R., Wilson, B., Grellier, K., Barton, T.R., Hammond, P.S. \& Thompson, P.M. (2004) Parallel influences of climate on the behaviour of Pacific killer whales and Atlantic bottlenose dolphins. Ecology Letters, 7, 1068-1076.

MacGarvin, M. \& Simmonds, M.P. (1996) Whales and climate change. In The Conservation of Whales and Dolphins - Science and Practice (eds M.P. Simmonds \& J.D. Hutchinson), pp. 321-332. John Wiley and Sons, Chichester, UK. 
Macleod, C.D., Bannon, S.M., Pierce, G.J., Schweder, C., Learmouth, J.A., Herman, J.S. \& Reid, R.J. (2005) Climate change and the cetacean community of north-west Scotland. Biological Conservation, 124, 477-483.

McCarthy, J.J., Canziani, O.F., Leary, N.A., Dokken, D.J. \& White, K.S. (eds) (2001) Climate Change 2001: Impacts, Adaptation and Vulnerability. Contribution of Working Group II to the Third Assessment Report of the Intergovernmental Panel on Climate Change, Cambridge University Press, Cambridge, UK.

Moore, S.E., Grebmeier, J.M. \& Davies, J.R. (2003) Gray whale distribution relative to forage habitat in the northern Bering Sea: current conditions and retrospective summary. Canadian Journal of Zoology, 81, 734-742.

Perry, A.L., Low, P.J., Ellis, J.R. \& Reynolds, J.D. (2005) Climate change and distribution shifts in marine fishes. Science, 308, 1912-1915.

Robinson, R.A., Learmouth, J.A., Hutson, A.M., Macleod, C.D., Sparks, T.H., Leech, D.I., Pierce, G.J., Rehfisch, M.M. \& Crick, H.Q.P. (2005) Climate Change and Migratory Species. BTO Research Report 414 [http://www.defra.gov.uk, accessed 23 November 2006].

Simmonds, M.P. (2004) Whales and Dolphins of the World. New Holland Publishers, London, UK.

Simmonds, M.P. \& Mayer, S.J. (1997) An evaluation of environmental and other factors in some recent marine mammal mortalities in Europe: implications for conservation and management. Environmental Review, 5, 89-98.

Stern, N. (2006) The Economics of Climate Change - The Stern Review. Cambridge University Press, Cambridge, UK [also available at http://www.hm-treasury.gov.uk/ independent_reviews/stern_review_economics_climate_ change/sternreview_index.cfm, accessed 21 Decmber 2006].

TRS (The Royal Society) (2005) Ocean Acidification Due to Increasing Atmospheric Carbon Dioxide. The Royal Society, London, UK.

Whitehead, H. (1997) Sea surface temperature and the abundance of sperm whale calves off the Galapagos Islands: implications for the effects of global warming. Report of the International Whaling Commission, 47, 941-944.

Worms, B., Sandow, M., Oschlies, A., Lotze, H.K. \& Myers, R.A (2005) Global patterns of predator diversity in the open oceans. Science, 309, 1365-1369.

Würsig, B., Reeves, R.R. \& Ortega-Ortiz, J.G. (2002) Global climate change and marine mammals. In Marine Mammals Biology and Conservation (eds P.G.H. Evans \& J.A. Raga), pp. 589-608. Kluwer Academic/Plenum Publishers, New York, USA.

WWF (2002) Polar Bears at Risk; A WWF Status Report, May 2002. WWF, Washington, DC, USA.

\section{Biographical sketches}

Mark Simmonds is the Director of Science at WDCS (the Whale and Dolphin Conservation Society). His principle research interests include evaluating the significance of indirect threats to marine mammals, including a series of studies focused on the effects of chemical pollution, and marine conservation policy. Recently the WDCS science team has also been investigating the significance of manmade noise in the seas and taking part in field studies looking at the biology and status of marine mammals. Details of much of this work can be found on the WDCS website (http://www.wdcs.org). Mark has been a member of the Scientific Committee of the International Whaling Commission for over a decade.

Stephen Isaac's background is in environmental sciences. He worked as part of the WDCS international science team until recently, when he moved to work for an environmental consultancy. His research interests are currently focused on climate change and its impacts on flora and fauna.

\section{Postscript}

MacLeod et al. (2007) have recently reported a high incidence of harbour porpoises in Scottish North Sea waters dying from starvation as a result of dwindling sand eel stocks. The sand eel decline is linked to climate change. A baseline period (spring 1993-2001) was compared with data from spring 2002 and 2003. Diet was found to have changed between these two periods with sand eels making up a much smaller proportion of stomach contents in the key period of the spring in recent years. In the baseline period only $5 \%$ of stranded porpoises examined died of starvation, whereas starvation was the cause of death of 33\% from 2002 and 2003. The sand eel spawning stock biomass and recruitment in the North Sea were substantially lower in 2002 and 2003 than during the baseline period.

MacLeod, C.D., Begoña Santos, M., Reid, R.J., Scott, B.E. \& Pierce, G.J. (2006) Linking sand eel consumption and the likelihood of starvation in harbour porpoises in the Scottish North Sea: could climate change mean more starving porpoises? Biology Letters, doi:10.1098/ rsbl.2006.0588, published online. 